\title{
Parents refusing blood transfusions for their children solely on religious grounds: Who must apply for the court order?
}

\author{
D J McQuoid-Mason, BComm, LLB, LLM, PhD \\ Centre for Socio-Legal Studies, University of KwaZulu-Natal, Durban, South Africa
}

Corresponding author: D J McQuoid-Mason (mcquoidm@ukzn.ac.za)

\begin{abstract}
The South African Constitution provides that children have the right to healthcare, as well as all other rights. Furthermore, in all matters affecting them, their best interests must be 'of paramount importance'. It seems common practice that, when parents refuse blood transfusions for their children solely on religious grounds, doctors and health authorities apply for a court order to overturn such refusals. However, since the implementation of the Children's Act of 2005, it may be that the onus is no longer on doctors and authorities to apply to court to reverse the decision of parents and guardians. It can be argued instead that the burden has shifted to the parents to apply to court for an order to overrule the decision of doctors, by proving to the court that alternative choices are available. Guidance is given for situations, particularly in the public sector, where alternative choices are not available.
\end{abstract}

S Afr Med J 2020;110(2):100-101. https://doi.org/10.7196/SAMJ.2020.v110i2.14486

It appears that in nearly all cases where parents refuse blood transfusions for their children solely on religious grounds, in some provinces in the public sector doctors and health authorities are being advised to seek a court order to overcome the parents' refusal. According to newspaper reports, this also happens in situations where parents have continued to object, even after the necessary court order has been obtained. ${ }^{[1]}$ The question arises whether, given the provisions of the Children's Act of $2005,{ }^{[2]}$ the parents - not the doctors - are obliged to obtain a court order. The question can be reframed as follows: do the parents, guardians or caregivers have to apply to reverse the decision by doctors to give such a child a blood transfusion to save the child's life? Or, do the doctors have to apply to court to overcome the refusal to consent by the parents, guardians or caregivers to the child receiving a blood transfusion?

To answer this question, it is necessary to consider the provisions of the South African Constitution ${ }^{[3]}$ and the Children's Act ${ }^{[2]}$ to conclude who should apply for the court order.

\section{The Constitution}

The Constitution ${ }^{[3]}$ provides that everyone has 'the right to freedom of conscience, religion, thought, belief and opinion' (section 15(1)), which applies to the parents and guardians of child patients. The Constitution also states that persons belonging to a religious community may not be denied the right to practise their religion (section 31(1)), provided such religious beliefs are not 'exercised in a manner inconsistent with any provision in the Bill of Rights' (section 15(1)).

The Constitution ${ }^{[3]}$ further states that everyone has the right of access to healthcare (section 27(1)) and that children, in particular, have the right to healthcare (section 28(3)(a)). Children, like everyone else, also have the right to life (section 11), and the right not to be refused emergency medical treatment (section 27(3)). The Constitution is also clear that the 'best interests' of the child 'are of paramount importance in every matter concerning a child' (section 28(3)). It is submitted, therefore, that during medical emergencies, the rights of child patients not to be refused emergency medical treatment (section 27(3)) and to exercise their right to life (section 11), may not be undermined by their parents' right to freedom of religion (section 15(1)). ${ }^{[4]}$

When alternative therapies to blood transfusions are available ${ }^{[5]}$ and the necessary resources exist for their application, these therapies should be offered. This is also provided for in the Children's Act ${ }^{[2]}$ (section 129(10)). However, if such therapies are not available when a medical emergency demands a blood transfusion, the parents may not refuse to allow a doctor to treat a child patient in need of urgent life-saving treatment. Such a refusal would be a clear violation of the child's constitutional rights to life and the child may not be refused emergency medical treatment. ${ }^{[4]}$

For example, in a Gauteng High Court case, ${ }^{[4]}$ which was decided prior to the introduction of the Children's Act, ${ }^{[2]}$ where the parents had refused to consent to a life-saving blood transfusion for their baby, a paediatrician applied for an urgent order to allow her to give the child a transfusion. The parents opposed the doctor's application on religious grounds and because they were worried about the risks of infection associated with blood transfusions. The doctor had mentioned in her court application that if the transfusion was not given the baby would probably die. ${ }^{[4]}$

The High Court held that in light of the evidence, the parents' concerns regarding infected blood were unfounded. It also held that while the parents' religious beliefs had to be respected, these were not more important than the baby's right to life and other constitutional rights, including the 'best interests' of the child. ${ }^{[4]}$ Accordingly, the Court made an order allowing an immediate blood transfusion. Since then, the Children's Act ${ }^{[2]}$ has specifically outlawed refusals to consent solely on religious grounds by parents or guardians to treatment of their children (section 129(10)). 


\section{Effect of the Children's Act}

The Children's Act ${ }^{[2]}$ sets out the conditions for consent when children are not old enough and of sufficient maturity to consent to medical treatment or surgical operations (section 129). With regard to medical treatment, consent may be given by a parent, guardian or caregiver (section 129(4)). In the case of surgical operations, consent may be given by a parent or guardian (section 129(5)). In emergency situations, where there is no time to obtain the necessary consent for treatment or surgery, the superintendent or person in charge of a hospital may give consent (section 129(6)). If the parent or guardian of a child unreasonably refuses to give consent or assist a child, or is incapable of doing so, or cannot be traced or is deceased, the Minister of Health may consent to the necessary treatment or surgical operation (section 129(7)).

In addition, the Children's Act states:

'A High Court or a children's court may consent to the medical treatment of or surgical operation on a child in all instances where another person that may give consent in terms of this section refuses or is unable to give consent.' (Section 129(8))

However, the Act goes on to provide that:

'No parent, guardian or caregiver of a child may refuse to assist a child $\ldots$ or withhold consent $\ldots$ by reason only of religious or other beliefs, unless that parent or guardian can show that there is a medically acceptable alternative choice to the medical treatment or surgical operation concerned.' (Section 129(10))

Therefore, the Act places the onus squarely on the parent or guardian who objects to medical treatment or surgery being performed on a child to 'show that there is a medically acceptable alternative choice' (section 129(10)). This clearly indicates that the burden of proof is placed on the parent or guardian to show the court that such an alternative is available and medically indicated.

\section{Conclusions}

The Children's Act ${ }^{[2]}$ states that generally a High Court or children's court may consent to medical treatment of a child or a surgical operation on a child, where the person legally entitled to do so refuses or is unable to give consent (section 129(8)). However, the Act also places a burden of proof on persons who refuse to consent, to show that there is 'a medically acceptable alternative choice' available (section 129(10)). It is submitted that this implies that parents or guardians who refuse to consent solely on religious grounds need to apply to court to prove that doctors have an alternative remedy, which is not being offered.

Accordingly, it is submitted that it is not necessary for doctors to make a court application order to confirm that they are upholding the law and to justify their conduct. They only have to do this once the parents or guardians have applied to court alleging that an alternative medically indicated therapy exists and is not being offered. Certainly, if a court order has already been granted that allows doctors to transfuse the child, and the parents refuse to obey it, ${ }^{[1]}$ they are guilty of contempt of court - unless they have appealed against the judgment to a higher court. In such instances, there is no reason for the doctors to go back to court to confirm the previous judgment authorising the transfusion, unless they are opposing an appeal against such judgment by the parents or guardians.

In the public sector, if the alternative therapy is not available owing to a shortage of resources, and the public sector doctors and authorities can indicate that the remedies the sector offers are reasonable and justifiable, there is no legal liability on their part. ${ }^{[6]}$ However, if such alternative remedies are available in the private sector, and time is not of the essence, the parents or guardians should be given an opportunity to transfer their child from the public sector and make the necessary arrangements with the relevant private sector institution to have their child treated with alternative therapies.

Declaration. None.

Acknowledgements. None.

Author contributions. Sole author.

Funding. National Research Foundation.

Conflicts of interest. None.

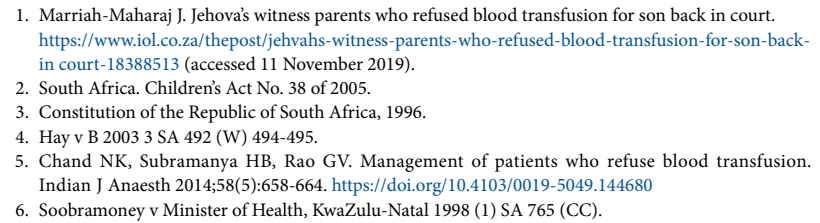

Accepted 25 November 2019. 